\title{
REDUNDANCY ANALYSIS OF THE INFLUENCE OF METAL CONTENT AND OTHER EDAPHIC PARAMETERS ON THE CO- EXSISTENCE OF TRICHODERMA SPECIES
}

\author{
Z. NAÁR* - A. DOBOS \\ Eszterházy Károly College \\ H-3300 Eger, Leányka str. 6., Hungary \\ (phone: +36-36-520-400; fax: +36-36-520-446) \\ *e-mail:naarzo@ektf.hu \\ (Received $10^{\text {th }}$ Sep 2005, accepted $10^{\text {th }}$ Oct 2006)
}

\begin{abstract}
The growth requirements of Trichoderma fungi that are wide spread saprotrophic soil microorganisms, are quite similar, therefore it is essential to define the environmental factor(s) along which they divide the available ecological niches. For this reason, we determined chemical and physical properties of 24 soil samples from different localities of Hungary, the presence of Trichoderma species and the relationships between two groups of data were analyzed with different statistical methods. The coexistence of 13 identified Trichoderma spp. proved to be a general phenomenon, which provided a good opportunity to explore the dividing environmental factors. Only redundancy analysis gave a reasonable model from 26 abiotic soil parameters. However, the number of variables was two times higher than that of species, thus the model was built in step-by-step process during which the explanation power of parameters was assessed with Monte Carlo permutation test. The best possible model of 13 soil properties explained $66.19 \%$ of variance in the occurrence of Trichoderma species. Their positions in the triplots showed the separation of their niches along some of the investigated abiotic environmental variables. The available $\mathrm{Zn}$-content had the highest explaining power however the in vitro zinc tolerance test did not justify its importance.
\end{abstract}

Keywords: Trichoderma spp., coexistence, edaphic parameters, redundancy analysis, niche separation

\section{Introduction}

Trichoderma species are worldwide spread common soil microorganisms and have a potential in biological control of plant pathogenic fungi [1]. In spite of their abundance and importance as litter decomposers as well as biocontrol tools, their ecology is not well understood considering their occurrence and coexistence. Although these species are often isolated from various samples containing organic materials [8], difficulties of their exact taxonomic identification have slowed the development of their ecology. The morphologically and physiologically similar Trichodermas are often represented by more than one species in the same habitat $[24,25,26]$. This phenomenon raises the need for detailed study, how they avoid the competitive exclusion [11]. The possibilities for niche separations are the differences in exploited microhabitat, utilized substrates and/or period of activity [21]. Advances on the coexistence of Trichoderma spp. were restricted to the clarification of the role of temperature. It was established that the sympatric species might share their available ecological space along the fluctuating temperature through seasons: the cold adapted ones like $T$. polysporum and $T$. viride proliferated from autumn to spring, whereas the other species having higher growth temperature optima (like $T$. harzianum and $T$. koningii) were more active during 
summer [26]. To our knowledge, no further abiotic environmental parameters were investigated in details to explain the coexistence of Trichoderma spp.

The aims of this study were to clarify the possible role of several abiotic soil characteristics on the occurrence of Trichoderma spp. in various soil types and to reveal whether the expected niche separation can be observed along those environmental parameters.

\section{Materials and methods}

\section{Soil samples}

Soil samples were collected late Spring at 24 localities to represent each main soil types occurring in Hungary. All of sampling sites were arable fields of various cultivation history with exception of site Sopron where the sample was collected from a beech forest. After removing plant debris from the surface, about $10 \mathrm{~kg}$ soil of Ahorizon was taken in plastic bag from $1 \mathrm{~m}^{2}$, and was left opened to preserve aerobic conditions. Soil samples were stored at a dry cool place until using within two weeks.

\section{Physico-chemical analysis of soil samples}

Each sample was thoroughly homogenized and subsample of $1 \mathrm{~kg}$ was taken to determine the following 24 physico-chemical properties of soil: $\mathrm{pH}_{(\mathrm{KCl})}$, compaction (according to Arany), $\mathrm{CaCO}_{3}$ content, total water soluble salt content, amount of organic carbon as humus content; $\mathrm{KCl}$-soluble $\mathrm{Mg}$, nitrite+nitrate nitrogen, and ammonium content; $\mathrm{EDTA}+\mathrm{KCl}$ soluble $\mathrm{Cu}, \mathrm{Zn}$, Mn content; ammonium-lactate soluble $\mathrm{K}_{2} \mathrm{O}, \mathrm{Na}$, and $\mathrm{P}_{2} \mathrm{O}_{5}$ content; granulometric composition: pebble $(>5 \mathrm{~mm})$, gravel $(2-5 \mathrm{~mm})$, total sand $(0.02-2 \mathrm{~mm})$ separated to coarse sand $(0.5-2 \mathrm{~mm})$, medium sand $(0.2-0.5 \mathrm{~mm})$, small sand $(0.1-0.2 \mathrm{~mm})$, fine sand $(0.05-0.1 \mathrm{~mm})$, very fine sand $(0.02-$ $0.05 \mathrm{~mm})$, silt $(0.002-0.02 \mathrm{~mm})$, clay $(<0.002 \mathrm{~mm})$. The measurement of the above parameters was made by Hajdú-Bihar County Station of Plant Protection and Soil Preservation Department (Debrecen) according to the Hungarian Standards.

\section{Isolation and identification of Trichoderma fungi}

A modified washing and plating method [20] was used to check the presence of Trichoderma fungi in soil. Subsample of $200 \mathrm{~g}$ soil was blended for $30 \mathrm{~s}$ with $350 \mathrm{~cm}^{3}$ sterile tap water and sieved through $0.1 \mathrm{~mm}$ mesh. The remained material were placed in the apparatus and washed with continuous flow of sterile tap water $\left(0.3 \mathrm{dm}^{3} \mathrm{~min}^{-1}\right)$ to obtain particles that are colonized by growing hyphae. After $20 \mathrm{~min}$ washing during which the apparatus was gently shaken on orbital shaker $\left(20 \mathrm{rev} \mathrm{min}^{-1}\right), 50$ randomly chosen particles of 1-2 mm fraction were plated in Trichoderma-selective medium [2] containing Petri dishes $(120 \mathrm{~mm}$ diam.) in five replicates. Plates were than incubated for 10 days at $22{ }^{\circ} \mathrm{C}$ under continuous fluorescent light. Pure culture of each developing colonies were prepared by transferring of hyphal inoculum on PDA (Oxoid) slants. For identification, the macroscopic features of pure grown colonies were observed on oatmeal agar, potato-dextrose agar, or malt-extract agar, and the microscopic ones were surveyed with lactophenol cotton-blue staining. Trichoderma isolates were taxonomically identified $[22,3,4,5,6]$. 


\section{Measurement of zinc tolerance of $\mathrm{T}$. harzianum strains}

The zinc content proved to the most effective explanatory factor for variance of Trichoderma spp. therefore we assessed their reaction to the zinc concentration measured in the particular soils, and determined the minimum inhibitory concentration that cause total lack of spore germination. T. harzianum strains were used because this species occurred in 22 of 24 soil samples. Spore suspensions were prepared from 5 days old cultures and 1-15 mM concentration series of $\mathrm{ZnSO}_{4}$ solution made in $2 \%$ pepton water was inoculated in microtiter plates with three replications. Lack of germination was registred after 48 hours of incubation at $25^{\circ} \mathrm{C}$.

\section{Statistical analysis}

Although the population density of Trichoderma spp. was counted as number of colony developing soil particles, the presence data (+ or -$)$ of particular species were used for statistical analysis because some unmeasured environmental factors (such as season history of soil temperature and water content) might greatly influence the population size of particular species. The incidence of species was summarized in a cooccurrence matrix that showed the numbers of soils, from which two particular species could have been isolated. The theoretical probability of coexistence was calculated with multiplication of their observed incidence rates (number of incidence divided with 24, the number of soil samples). The observed probability was obtained with division of coexistence cases and the number of soil samples (24). Pearsons's non-parametric correlation analysis was performed to reveal the relationships between the occurrence of particular Trichoderma species and each of soil parameters as single factors. Before analysis, the data of 24 soil properties were classified into four groups according to quartiles. The soil type as complex parameter and the vegetation of collection site were also tested with codes listed in Table 1. The presence of Trichoderma species was introduced as presence-absence value of 1 or 0 . Because of insignificant result of correlation analyses, redundancy analyses were performed to quantify the extent to which the occurrence of Trichoderma spp. can be explained by combinations of soil properties. The number of environmental variables was too high to introduce all of them in one analysis because it might not be higher than 13, the number of Trichoderma species. Therefore, a forward selection of variables was achieved, in tandem with Monte Carlo Permutation test. The randomization was performed as similar as McCune [18] did it. Shuffle of the environmental matrix (variables on the right) by rows preserved the species matrix and the structures of correlations among soil parameters but it destroyed the relationship between species and environmental data. One hundred randomizations of 576 possible different permutations were used for each analysis. Those ordinations were accounted to be significant, of which total explained species matrix variation were higher than that of at least 95 randomizations. The RDA process was carried out with SYNTAX 2000 [1].

\section{Results}

\section{Occurrence of Trichoderma fungi in various soil types}

Trichoderma fungi were present in all of 24 soil samples. The number of species inhabiting the same soil ranged from 1 to 5 . No conspicues relationship could be found 
between the soil type and the species composition. Three species hosting soils were found most commonly, in 7 of 24 cases. It was followed by single and two species hosting soils (5-5 samples). Four species were found in four samples, five species were isolated from three ones. Soils hosting single species had some extreme properties: high salt content in solonchak-solonetz (Sample 16), solonchak (Sample 17), high organic matter content in peat soil (Sample 24), raw texture in alluvial soil (Sample 22). However, one of two pseudomycelier chernozem soils (Sample 4) that had neither extreme property hosted also only one species. In contrast, three species could be isolated from the other sample of this soil type (Sample 5). In four of five cases, $T$. harzianum was found in these soils, and $T$. viride was isolated from one single species hosting soil. The five species hosting soils belonged also to different main soil types: meadow chernozem with salt accumulation in the deeper layers (Sample 8), rust-colored forest soil (Sample 13), and solonetzic meadow soil (Sample 21). Their species composition differed greatly; no common species were detected.

\section{Coexistence of Trichoderma spp.}

Trichoderma spp. associated with different ranges of other species (not shown) suggesting some associability. There was no species, which would associate with all the other 12 species or with no other species. Although T. harzianum was detected in 20 of 24 soil samples, and it coexisted with 10 of 12 other species. T. harzianum never coupled with $T$. koningii or $T$. hamatum raising the possibility of their competitive exclusion by $T$. harzianum. However, it coupled frequently with $T$. virens: in 13 soil samples of possible 14 cases, which gave higher observed probability $(\mathrm{p}=0.542)$ than the theoretical one $(\mathrm{p}=0.486)$ for common occurrence. Similar tendency was found for the relationship of $T$. harzianum to $T$. atroviride. The theoretical probability of coexistence of $T$. harzianum with $T$. viride was the same as the observed one, thus, their coexistence seemed to be rather a random phenomenon. In contrast, the difference between the observed and the theoretical frequency of common existence of $T$. harzianum with $T$. tomentosum was considerably (by $9.7 \%$ ) lower, suggesting some competence between them. The case was similar for the occurrence of $T$. tomentosum with $T$. virens, which was not a surprise considering the common occurrence of $T$. harzianum and $T$. virens. The rare species (T. koningii, T. hamatum, T. longipilis, $T$. polysporum, T. strigosum, and T. strictipilis, ) that have only one representative, never coupled with one another, with the exception of the first two species that were found in the same soil sample.

Table 1. Collection site, soil type, vegetation and occurring Trichoderma fungi of applied soil samples in Hungary.

\begin{tabular}{|c|c|c|c|c|}
\hline No. & Origin & Soil type (code) & $\begin{array}{c}\text { Vegetation } \\
\text { (code) }\end{array}$ & Trichoderma species \\
\hline 1 & Gödöllö & humous sandy soil (1) & tomato 81 ) & T. harzianum, T. virens \\
\hline 2 & Mélykút & chernozem-type sandy soil (1) & wheat (2) & T. harzianum, T. virens \\
\hline 3 & Izsák & calcareous blown sand (1) & rye (2) & T. harzianum, T. virens \\
\hline 4 & Nagyigmánd & pseudomycelier chernozem (2) & corn $(1)$ & T. harzianum \\
\hline 5 & Érd & pseudomycelier chernozem (2) & corn (1) & T. harzianum, T. virens, T. viride \\
\hline 6 & Martonvásár & $\begin{array}{l}\text { chernozem brown forest soil } \\
\text { (2) }\end{array}$ & wheat (2) & $\begin{array}{l}\text { T. atroviride, } T \text {. harzianum, } T \text {. } \\
\text { virens, } T \text {. viride, }\end{array}$ \\
\hline
\end{tabular}




\begin{tabular}{|c|c|c|c|c|}
\hline No. & Origin & Soil type (code) & $\begin{array}{l}\text { Vegetation } \\
\text { (code) }\end{array}$ & Trichoderma species \\
\hline 7 & Kondoros & lowland chernozem (2) & wheat (2) & $\begin{array}{l}\text { T. harzianum, T. virens, T. viride, } \\
\text { T. minutisporum }\end{array}$ \\
\hline 8 & Nagyszénás & $\begin{array}{l}\text { lowland chernozem with salt } \\
\text { accumulation in the deeper } \\
\text { layers }(2)\end{array}$ & corn $(1)$ & $\begin{array}{l}\text { T. atroviride, T. harzianum, T. } \\
\text { virens, T. longipilis, T. tomento- } \\
\text { sum, }\end{array}$ \\
\hline 9 & Csanádapáca & meadow chernozem (2) & wheat (2) & $\begin{array}{l}\text { T. harzianum, T. virens, T. viride, } \\
\text { T. polysporum }\end{array}$ \\
\hline 10 & Székkutas & $\begin{array}{l}\text { meadow chernozem with salt } \\
\text { accumulation in the deep (2) }\end{array}$ & $\begin{array}{l}\text { sunflower } \\
\text { (1) }\end{array}$ & T. harzianum, T. virens \\
\hline 11 & Kapoly & brown earth (3) & potato (1) & T. tomentosum, T. minutisporum \\
\hline 12 & Sopron & brown forest soil (3) & $\begin{array}{l}\text { beach forest } \\
\text { (3) }\end{array}$ & $\begin{array}{l}\text { T. atroviride, T. harzianum, } T \text {. } \\
\text { viride, T. tomentosum }\end{array}$ \\
\hline 13 & Máriabesnyő & rust-coloured forest soil (3) & wheat (2) & $\begin{array}{l}\text { T. viride, T. tomentosum, } T \text {. } \\
\text { hamatum, T. koningii, T. spirale }\end{array}$ \\
\hline 14 & Nagyrécse & $\begin{array}{l}\text { brown forest soil with clay } \\
\text { illuviation (3) }\end{array}$ & corn (1) & T. harzianum, T. virens, T. viride \\
\hline 15 & Lenti & pseudogley (3) & corn $(1)$ & T. harzianum, T. virens, T. spirale \\
\hline 16 & $\begin{array}{l}\text { Kunszentmik- } \\
\text { lós }\end{array}$ & solonchak-solonetz (4) & rape $(2)$ & T. harzianum \\
\hline 17 & Apaj & solonchak (4) & $\begin{array}{l}\text { sunflower } \\
\text { (1) }\end{array}$ & T. viride \\
\hline 18 & Mezőtúr & $\begin{array}{l}\text { meadow solonetz turning into } \\
\text { steppe formation (4) }\end{array}$ & corn $(1)$ & $\begin{array}{l}\text { T. harzianum, T. strigosum, } T \text {. } \\
\text { viride }\end{array}$ \\
\hline 19 & Szentes & meadow solonetz (4) & $\begin{array}{l}\text { sunflower } \\
\text { (1) }\end{array}$ & T. harzianum, T. virens, T. viride \\
\hline 20 & Szászberek & meadow soil (5) & alfalfa (3) & $\begin{array}{l}\text { T. atroviride, T. harzianum, } T \text {. } \\
\text { virens, }\end{array}$ \\
\hline 21 & Szarvas & solonetzic meadow soil (5) & corn $(1)$ & $\begin{array}{l}\text { T. atroviride, T. harzianum, } T \text {. } \\
\text { strictipilis, } T \text {. virens, } T \text {. viride }\end{array}$ \\
\hline 22 & Vág & alluvial soil (6) & alfalfa (3) & T. harzianum \\
\hline 23 & Pörböly & $\begin{array}{l}\text { alluvial soil with high humus } \\
\text { content (6) }\end{array}$ & $\operatorname{corn}(1)$ & $\begin{array}{l}\text { T. atroviride, T. harzianum, } T \text {. } \\
\text { viride }\end{array}$ \\
\hline 24 & Nádasdladány & partly decomposed peat (7) & $\begin{array}{l}\text { sunflower } \\
\text { (1) }\end{array}$ & T. harzianum \\
\hline
\end{tabular}

\section{Selection of important environmental variables with redundancy analysis}

Redundancy analyses were performed to find significant relationships between soil parameters and the presence of Trichoderma fungi, because the correlation analysis between did not reveal any noteworthy relationship. There was a problem during the redundancy analyses (RDA): the number of soil parameters two fold exceeded the maximum testable number of environmental variables that may not be higher than number of species. Thus, selections were carried out among the parameters in two groups of 13 chemical properties and the other 13 ones (11 physical properties, soil main type and the vegetation of collection site as categories) and. At first, the weight of soil parameters (as explaining environmental variables on the right side) was assessed with exclusion of one at a time. Those variables were used as first one in model building of which exclusion resulted in the highest decrease of eigenvalue of axis 1 (having the highest explaining power for variance of species data). RDA of physical properties without pebble and that of chemical ones without zinc content had the least explaining power, thus, these two parameters were used for model building with 
stepwise selection. For this process, all of the soil properties (with exception of starting ones) were used. They were tried to introduce one by one, RDA was carried out, and the sum of eigenvalues of axis 1 and 2 was calculated. In each step, that variable was built in, which caused the highest increase in summed eigenvalue. All new ordinations were tested for significance with Monte Carlo Method as described in Materials and methods. The model based on the pebble content proved not to be significant when the zinc content was not introduced, thus, we finished the model building only with zinc content based one. The introduction order of further variables was as follows: clay, $\mathrm{K}_{2} \mathrm{O}, \mathrm{P}_{2} \mathrm{O}_{5}$, $\mathrm{Cu}, \mathrm{CaCO}_{3}, \mathrm{Mn}$ content, rate of silt, $\mathrm{NH}_{4}$ content, vegetation, rate of coarse sand, total sand rate, and $\mathrm{pH}_{(\mathrm{KCl})}$. The ordination remained statistically significant until the introduction of the thirteenth variable. Moreover, further variables seemed to be introducible, when they were changed with the last one, however, they should have been omitted because of reaching of the maximum number of the model.

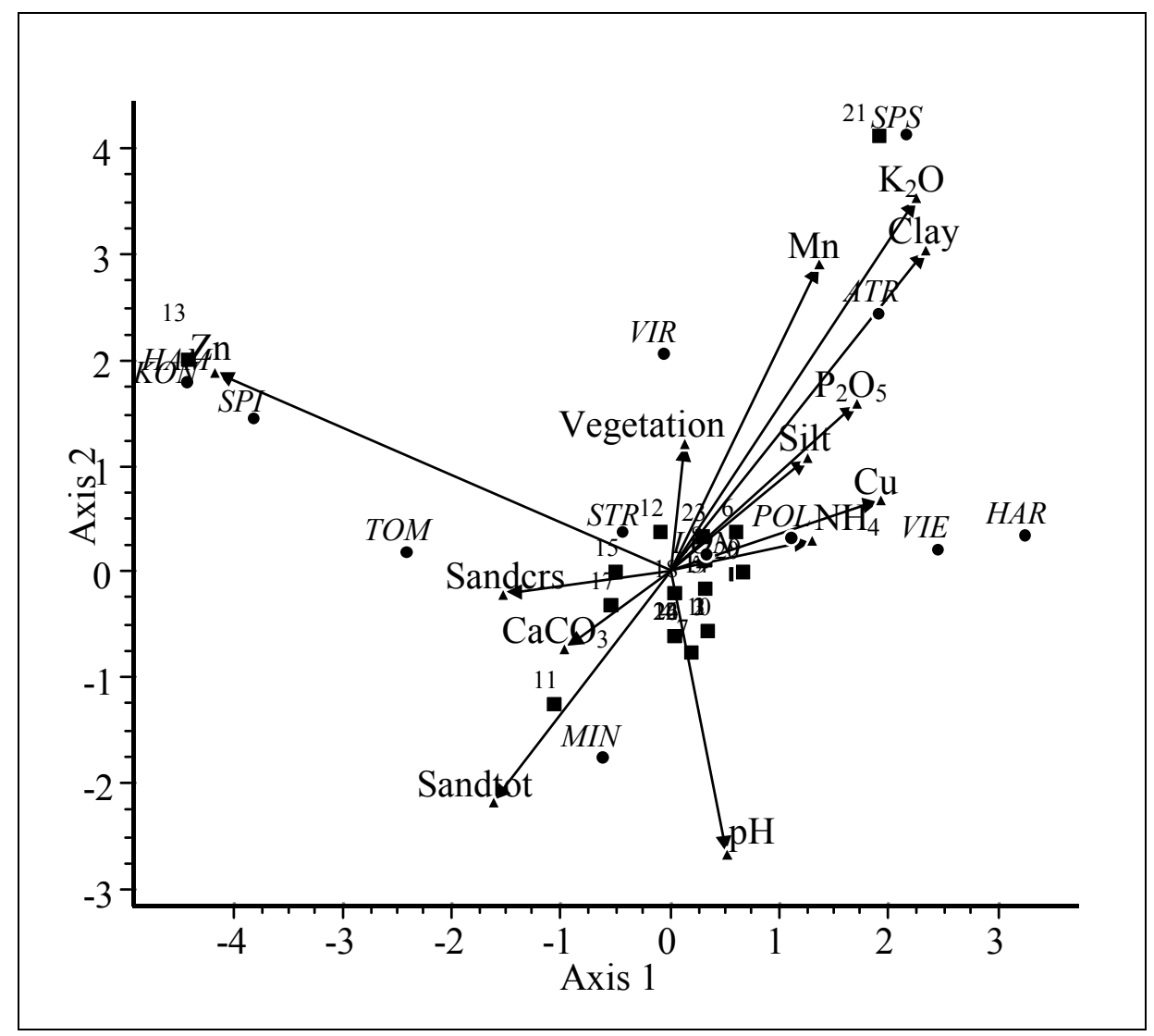

Figure 1. The most effective ordination of 24 soil samples as objects, 13 Trichoderma species as variables on the left, and 13 soil parameters as variables on the right. Soil samples as objects are marked with rectangles and numbers (Table 1). Trichoderma species are marked with circles and abbreviations in italic as follows: ATR - T. atroviride, HAM-T. hamatum, HAR-

T. harzianum, KON - T.koningii, LON - T. longipilis, MIN - T. minutisporum, $P O L-T$. polysporum, SPI-T. spirale, SPS-T. strictipilis, STR - T. strigosum, TOM - T. tomentosum, $V I E-T$. virens, VIR - T. viride. Soil parameters are marked with triangles.

The abovementioned environmental variables of the best ordination (Fig. 1) explained total $66.18 \%$ of variance in the species data. The eigenvalues of Axis 1 and 2 
were 3.17 and 1.99 , respectively, and these axes together explained $39.71 \%$ of species data variance. According to the high explaining power, they correlated closely $(\mathrm{r}=$ 0.957 and 0.937 , respectively) with the occurrence of Trichoderma species. As the arrows show, the introduced environmental variables influenced the occurrence of Trichoderma spp. differently both in direction and the extent. According to the previous selection of the environmental variable, Axis 1, which is the most important in the evaluation of ordinations, was predominantly determined by the extractable $\mathrm{Zn}$ content of soil with $\mathrm{r}=-0.786$ value (Table 2). Axis 2 was determined by more variables: extractable $\mathrm{K}_{2} \mathrm{O}$, Mn content, rate of clay, and $\mathrm{pH}_{(\mathrm{KCl})}$.

Table 2. Correlation of environmental variables with ordination axes obtained with redundancy analyzis and showed on Fig. 1.

\begin{tabular}{l|c|c}
\hline \multirow{2}{*}{\multicolumn{1}{c}{ Environmental variables }} & \multicolumn{2}{c}{ Correlation with } \\
\cline { 2 - 3 } $\mathrm{Zn}$ content (available) & Axis 1 & Axis 2 \\
Clay content & -0.786 & 0.354 \\
$\mathrm{~K}_{2} \mathrm{O}$ content (available) & 0.443 & 0.574 \\
$\mathrm{P}_{2} \mathrm{O}_{5}$ content (available) & 0.426 & 0.669 \\
$\mathrm{Cu}$ content (available) & 0.325 & 0.301 \\
$\mathrm{CaCO}_{3}$ content & 0.365 & 0.129 \\
$\mathrm{Mn}_{n}$ content (available) & -0.181 & -0.138 \\
$\mathrm{Silt}$ content & 0.26 & 0.549 \\
$\mathrm{NH}_{4}$ content (available) & 0.239 & 0.202 \\
$\mathrm{Vegetation}$ of collection site & 0.247 & 0.057 \\
$\mathrm{Coarse}$ sand content & 0.028 & 0.229 \\
Total sand content & -0.288 & -0.038 \\
$\mathrm{pH}_{(\mathrm{KCl})}$ & -0.304 & -0.41 \\
\hline
\end{tabular}

The species were rather scattered in the triplot, however, some associations also seemed to be present. The proximity of $T$. harzianum and $T$. virens supported their associability suspected from the coexistence matrix. The other frequent species $(T$. viride and T. atroviride) having representatives in at least $25 \%$ of the soil samples were clearly separated from them. The close position of $T$. hamatum and $T$. koningii, or $T$. strictipilis and $T$. strigosum might be only random phenomenon, because they have only one representative pro species.

\section{Measurement of zinc tolerance of Trichoderma fungi}

The growth of the tested T. harzianum strains did not change significantly due to the zinc level measured in the originating soil samples. The minimum inhibitory concentration (MIC) that cause total lack of spore germination was always above the zinc content of given soil samples and differed by strains in the range 5-14.3 mM. No marked correlation could be revealed between available zinc content of soil and the MIC value of T.harzianum strain isolated from the particular soil sample (Fig. 2). 


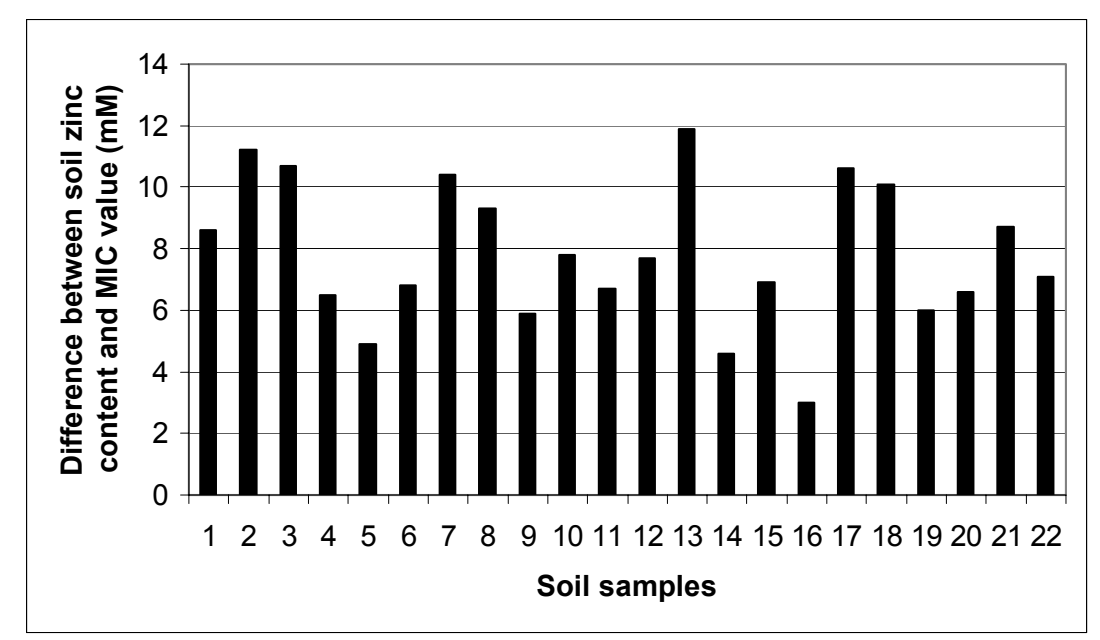

Figure 2. The difference between available zinc content of soil samples and the minimum inhibitory concentration (MIC) of T. harzianum strains from the particular soil samples.

\section{Discussion}

Trichoderma species were present in all of the 24 investigated soil samples even in the raw textured soil types, which allowed a detailed analysis of the influence of soil characteristics. There are only a few similar works dealing with detailed analysis of Trichoderma population of soils. In the most comparable work [23] the analysis of the Trichoderma population of 12 soil samples collected from apple orchards at various sites of Wisconsin was performed and the data about co-occurrence of Trichoderma species was also investigated and reported. Although the tested range of soil texture was wider in our investigation, we found a similar species co-occurrence. They found that the number of species occurring in any one soil varied from two to five. The rates of the soils hosting a particular number of Trichoderma species were similar. Also in the Wisconsin soils, the three species hosting soils were the most frequent. T. harzianum was found to be the most frequent species. The occurrence of $T$. virens was somewhat lower in Wisconsin $(50 \%)$ than in Hungary $(58 \%)$. A further disagreement that $T$. viride was rarer $(25 \%$ comparing to our $50 \%$ data),

The common occurrence of Trichoderma spp. coupling with moderate number of species of the genus (compared to that of similarly common Penicillium) gave an excellent opportunity to test the influence of abiotic soil characteristics on their incidence. In redundancy analyzis (RDA), available zinc content of soil proved to be the most effective soil parameter as explanative environmental variable for the variance in the occurrence of Trichoderma species. Without it no significant ordination could be computed from those soil parameters $(\mathrm{pH}$, organic matter or humus content, rate of sand, silt and clay) that were determined and published in the most soil microbiological and biocontrol studies. No other researchers observed that the amount of zinc exert so strong influence on the incidence of any soil fungus. Although there are numerous works dealing with impact of heavy metals among them zinc, on the growth and activity of Trichoderma fungi $[10,13,14,15,16]$, no characteristic difference in the reaction to zinc was found among Trichoderma species. Our data on the zinc reaction of $T$. harzianum species agree with that statement. We assumed that the available zinc content lower than the minimum inhibitory concentration influences the growth and the survival indirectly through physiological processes in which this metal ion is involved. 
Further investigations are needed to clarify the fine differences between the studied species in the zinc requirement for survival in soil.

In earlier investigations, not all soil parameters that were combined with zinc content during redundancy analysis had been prove to exert more or less influence on the activity or population size of indigenous or applied Trichoderma fungi. The results of our work partly supported the findings of Duffy et al. [9]. The impact of percent clay, copper content, soil $\mathrm{pH}$ and available phosphorous content was strengthened, but not that of nitrate-nitrogen and soluble magnesium, which were omitted during our ordination analysis because of their less explanative value. Significant partial correlations between Trichoderma population size and calcium, magnesium, or manganese content of soil were found[7], but not for potassium content, agreeing with Duffy et al. [9]. Contrary, we found the extractable potassium content to be the third most important environmental variable (see Table 2). Beyond litter quality, organic matter, $\mathrm{pH}, \mathrm{KCl}$-extractable ammonium and phosphate were responsible for the differences in fungal communities of different birch stand sites [17]. All of these soil characteristics were among the thirteen most effective environmental variables in our investigation. Earlier it was concluded that the abiotic characteristics of soil are of less importance on the population size of Trichoderma species [23, 26]. In our investigation, however, the combinations of the abiotic soil parameters explained $66.19 \%$ of variation of species occurrence, and further soil parameters seemed to have influence, but their introduction was not allowed because of number restriction of explanative variables in RDA.

The niche separation of Trichoderma spp. was supported by our work: the species were widely scattered trough the triplot (Fig. 1). In accordance with many works, it was found that their co-occurrence is a common phenomenon, which had to be accounted for type of niche separation [11]. It was summarized that the possibilities of separation in three types: exploited microhabitat, utilized substrates, time of activity [21]. The seasonal fluctuation of the soil water content and the temperature might be among of the abiotic environmental variables along which the sympatric Trihoderma spp. shared their microhabitat [26]. These findings were demonstrated under laboratory conditions, too [25]. To our knowledge, however, there were no studies carried out that would give evidence for niche separation along other abiotic soil characteristics. The relative position of the detected species are quite fare from one another with exception of $T$. harzianum and $T$. virens suggesting that they share the ecological niche along the studied soil parameters. These two species may do it along other, not investigated environmental parameter(s). Thus, the often-used soil parameters such as organic matter content, $\mathrm{pH}$, sand-silt-clay ratio appeared to be good predictors, but not the best for the occurrence of Trichoderma spp, because the combination of zinc, clay, copper, potassium and phosphorous content explained considerably higher part of variance in species occurrence data. The often-isolated species seemed to have fairly separated niches that might explain their co-occurrence.

Acknowledgement. The partial support of the Hungarian Research Fund (OTKA F036445) is highly acknowledged. The authors wish to thank for valuable comments of J. Podani and B. McCune on ordination tests. 


\section{REFERENCES}

[1] Anonymous (2001): SYNTAX 2000. Computer programs for data analysis in ecology and systematics. User's Manual. - Scientia, Budapest. pp. 67.

[2] Askew, D.J., Laing, M.D. (1993): An adapted selective medium for the quantitative isolation of Trichoderma species. - Plant Pathology 42: 686-690.

[3] Bissett, J. (1991a): A revision of the genus Trichoderma. II. Infrageneric classification. Canadian Journal of Botany 69: 2357-2372.

[4] Bissett, J. (1991b): A revision of the genus Trichoderma. III. Section Pachybasium. Canadian Journal of Botany 69: 2373-2417.

[5] Bissett, J. (1991c): A revision of the genus Trichoderma IV. Additional notes on section Longibrachiatum. - Canadian Journal of Botany 69: 2418-2420.

[6] Bissett, J. (1992): Trichoderma atroviride. - Canadian Journal of Botany 70: 639-641.

[7] Bulluck III, L.R., Brosius, M., Evanlyo, G.K., Ristaino, J.B. (2002): Organic and syntehtic fertility amendments influence soil microbial, physical and chemical properties on organic and conventional farms. - Applied Soil Ecology 19: 147-160.

[8] Domsch, K.H., Gams, W. Anderson, T.H. (1980): Compendium of soil fungi. Vol. 1. Academic Press, London, England. pp. 794-809.

[9] Duffy, B., Ownley, B.H., Weller, D.M. (1997): Soil chemical and physical properties associated with suppression of take-all of wheat by Trichoderma koningii. Phytopathology 87: 1118-1124.

[10] Gadd, G.M., Ramsay, L., Crawford, J.W., Ritz, K. (2001): Nutritional influence on fungal colony growth and biomass distribution in response to toxic metals. - FEMS Microbiology Letters 204: 311-316.

[11] Hardin, G. (1960): The competitive exclusion principle. - Science 131: 1292-1297.

[12] Köhl, J., Schlösser, E. (1988): Occurrence and temperature requirements of four Trichoderma species from different regions and substrates. - Angewandte Botanik 62: 301-309.

[13] Kredics, L., Dóczi, I., Antal, Zs., Manczinger, L. (2001): Effect of heavy metals on growth and extracellular enzyme activities of mycoparasitic Trichoderma strains. Bulletin of Environmental Contamination and Toxicology 66: 249-254.

[14] Kredics, L., Antal, Zs., Manczinger, L., Nagy, E. (2001): Breeding of mycoparasitic Trichoderma strains for heavy metal resistance. - Letters in Applied Microbiology 33: 112-116.

[15] Kredics, L., Antal, Zs., Manczinger, L., Nagy, E. (2001): Isolation and characterization of heavy metal resistant mutants from mycoparasitic Trichoderma strains. - IOBC-WPRS Bulletin 24: 233-236.

[16] Ledin, M., Krantz-Rülcker, C., Allard, B. (1999): Microorganisms as metal sorbents: comparson with other soil constituents in multi-compartment systems. - Soil Biology and Biochemistry 31: 1639-1648.

[17] McLean, M. A., Huhta, V. (2002): Microfungal community structure in anthropogenic birch stands in central Finland. - Biology and Fertility of Soils 35: 1-12.

[18] McCune, B. (1997): Influence of noisy environmental data on canonical correpondence analysis. - Ecology 78: 2617-2623.

[19] Papavizas, G.C. (1985): Trichoderma and Gliocladium: biology, ecology, and potential for biocontrol. - Annual Review of Phytopathology 23: 23-54.

[20] Parkinson, D., Williams, S.T. (1961): A method for isolating fungi from soil microhabitats. - Plant and Soil 13: 347-355.

[21] Pianka, E. R. (1978): Evolutionary ecology. - Harper and Row, New York. pp. 416.

[22] Rifai, M.A. (1969): A revision of the genus Trichoderma. - Mycological Papers of Commonwealth Mycological Institute, Kew, Surrey, England, 116: 1-56. 
[23] Roiger, D.J., Jeffers, S.N., Caldwell, R.W. (1991): Occurrence of Trichoderma species in apple orchard and woodland soils. - Soil Biology and Biochemistry 23: 353-359.

[24] Söderström, B.E., Bååth, E. (1978): Soil microfungi in 3 Swedish coniferous forests. Holarctic Ecology 1: 62-72.

[25] Widden, P. (1984): The effects of temperature on competition for spruce needles among sympatric species of Trichoderma. - Mycologia 76: 873-883.

[26] Widden, P., Abitbol, J.-J. (1980): Seasonality of Trichoderma species in a spruce-forest soil. - Mycologia 72: 775-784. 